\title{
Estimation of alongshore sediment discharge on pebble and sandy beaches
}

\author{
Elena Bondareva ${ }^{1 *}$ \\ ${ }^{1}$ Sochi State University, 94, ul. Plastunskaya, Sochi, 354000, Russia
}

\begin{abstract}
A unified approach has been developed to assess the integral alongshore sediment transport for the conditions of heterogeneous pebble and sandy beaches. The energy formulas for determining the sediment discharge have been modified for the conditions for calculating the integral alongshore sediment transport on heterogeneous pebble and sandy beaches. For this, the coefficient included in the energy formulas is determined using the Ackers-White method.
\end{abstract}

\section{Introduction}

There are various approaches to determining the alongshore sediment discharge (energy, balance of forces, based on dimensional analysis) [1]. It should be borne in mind that most of the calculation formulas for the alongshore sediment flow were obtained from the dependences for sediment transport in open channels by replacing the bottom shear stresses in the channel flow $\tau_{0}$ by the bottom shear stresses from waves in the flow $\tau_{w c}$. This is how the well-known Bijker, Ackers-White, and Engelund-Hansen dependences were obtained [2]. Such an approach to the channel dynamics of sediment is based on the Du Boys equation [3] in which the sediment discharge is proportional to the bottom shear stress. Or the Schoklitsch method [3] is used, in which the sediment discharge is proportional to the energy of the water flow.

\section{Materials and methods}

Of all the approaches, the energy approach is most often used, which is able to estimate the discharge both on pebble and sandy beaches $[4,5]$. It is based on the fact that the flow rate of sediment in a water flow is proportional to the dissipation of the flow energy.

For example, the formula by CERC (US Coastal Engineering Research Center) is widely used to determine the alongshore sediment discharge on sandy beaches [4]:

$$
I=K \cdot P_{l}
$$

where $I$ - alongshore sediment discharge expressed in units of submerged weight $(\mathrm{N} / \mathrm{s})$;

$K$ - empirical coefficient equal to 0.41 ;

\footnotetext{
* Corresponding author: bondareva 05@mail.ru
} 
$P_{l}$-alongshore component of the wave energy flux;

$E C_{g}$ - wave energy flux along the coast.

$$
P_{l}=\left(E C_{g}\right)_{b} \sin \alpha_{b} \cos \alpha_{b}
$$

In (2), all wave characteristics refer to the wave breaking line.

Often (2) has not only different empirical coefficients, but also other features $[4,6,7]$. This is caused by the use of various wave parameters and units of measurement.

For example, Le Mehaute [7] in the CERC formula (1) determined the alongshore component of the wave energy flux (2) taking into account the refraction and transformation of waves at the depth of the first wave breaking (according to the linear wave theory):

$$
P_{l}=\frac{\rho g^{2}}{64 \pi} H_{0}^{2} T K_{R}^{2} \sin 2 \alpha_{b},
$$

where

$\rho_{w}$ - density of water;

$g$ - acceleration of gravity;

$H_{0}$ - deep water wave height;

$T$ - average wave period;

$K_{R}$ - refractive index,

$$
K_{R}=\left(\frac{\cos \alpha_{0}}{\cos \alpha_{b}}\right)^{1 / 2}
$$

$\alpha_{0}$ - the angle between the front of the waves and the coastline in deep water;

$\alpha_{b}$ - the angle between the breaking wave front and the coastline.

He proposed to express the angle of refraction along the breaking line $\alpha_{b}$ through the angle of refraction in deep water $\alpha_{0}$ and the steepness of waves in deep water:

$$
\alpha_{b}=\alpha_{0}\left(0.25+5.5 \frac{H_{0}}{L_{0}}\right),
$$

where $L_{0}$ - deep water wavelength,

$$
L_{0}=\frac{g T^{2}}{2 \pi}
$$

Combining relations (1) - (6), the volumetric alongshore sediment discharge (1.1) can be written in the form:

$$
Q=K \cdot A \cos \alpha_{0} \sin z \alpha_{0}
$$

where:

$$
A=2 \frac{\rho g^{2}}{64 \pi} T H_{0}^{2}
$$




$$
z=0.25+5.5 \frac{H_{0}}{L_{0}}
$$

Thus, in contrast to (1) and (2), formula (7) takes into account the refraction of waves and, therefore, is determined by the wave parameters in deep water.

Provided that the sediment discharge $Q$ is expressed in $\mathrm{m}^{3} /$ year (volumetric sediment discharge), the empirical coefficient, in contrast to (1), turns out to be equal to $7.5 \times 10^{3}$ [6].

Le Meshaute [7] emphasizes that this coefficient should be determined for the specific conditions of the investigated section of the coast.

Among other existing dependencies that estimate the flow rate on sandy beaches, (1) gives satisfactory results and is often used in engineering calculations.

A review of other formulas also used to estimate discharge on sandy beaches is presented in [4]. But their difference from (1) is that they integrally give less reliable results.

Various empirical relationships based on the energy approach are also used to determine the discharge on pebble beaches.

So, as a result of processing laboratory and field data, an empirical dependence is proposed [Shakhin V.M., 8]

$$
Q=0.0023 g\left(\frac{v}{D_{m}}\right)^{0,5}\left(H_{b} T\right)^{1,5} \sin 2 \alpha,
$$

where $v$ - kinematic fluid viscosity;

$D_{m}$ - average sediment size;

$H_{b}$ - wave height along the breaking line $10-15 \%$ coverage in the design storm system;

$g$ - acceleration of gravity;

$T$ - average wave period;

$\alpha$ - angle of refraction of waves.

The alongshore discharge of pebble sediments can also be calculated using the empirical dependence of V.A. Petrov, N.A. Yaroslavtseva. [9]

$$
Q=K \cdot \rho g^{2} H_{b}^{3} T D_{m}^{-1} \sin \alpha_{b} \cos \alpha_{b}
$$

Where

$H_{b}$ - wave height of i - \% probability along the collapse line (m);

$D_{m}$ - average size of sediment that composes the beach within the surf zone;

$T$ - average wave period;

$K$ - empirical coefficient for pebble beach conditions.

If $Q$ is expressed in units of submerged weight (N/s), then $K=2 \cdot 10^{-6}$.

Formula (11) was obtained experimentally by V.A. Petrov and N.A. Yaroslavtsev on a section of a pebble beach with an average slope from the breaking line to the top of the uprush of about 0.12 [9]. Compared with other existing dependencies, it has a fairly wide range of applicability and satisfactorily estimates sediment discharge [9].

Since all empirical dependencies have a limited range of applicability and cannot be used outside this range, the estimate of the flow rate under external conditions outside this range may be erroneous, and this error is not determined.

Formulas $(1)$ and $(10,11)$ are based on a single energy principle. Therefore, it can be assumed that these formulas are capable of estimating sediment discharge not only under the conditions under which they were obtained, but also in a wider range. That is, each of 
these formulas is capable of estimating the alongshore sediment flow rate on pebble and sandy beaches, provided that their coefficients are determined for the conditions of the study area. This approach is caused by the fact that it is in the empirical coefficient that the properties of the beaches (slope, current velocity, sediment size) are largely incorporated, which form the characteristic processes described in [10] and have a dominant effect on the flow rate.

Moreover, there have already been attempts to use (1) to estimate the discharge on pebble beaches by determining a new coefficient for sediments, the particle size of which is more than $1 \mathrm{~mm}[1]$.

The coefficient (0.01) was proposed, which, like the coefficient in (1), claims to be a universal one, but, unfortunately, the obtained coefficient did not justify itself, and also requires determination not as a constant value, but as a function of the conditions of the studied area. That is, if it is used for wave conditions and conditions of the studied beach, different from those under which this coefficient was obtained, the estimate will be erroneous.

For example, Figure 1 shows a comparison of the results of predicting the alongshore flow of pebble sediments, determined by formula (1) with a coefficient of 0.01 and measured on a specific section of a pebble beach with a slope of 0.1 , with an average sediment size of $20 \mathrm{~mm}$ [86] (measured average annual sediment discharge at the section is $15300 \mathrm{~m}^{3} /$ year).

The gray bar denotes the range of values of the measured flow rate with a dispersion of $7650 \mathrm{~m}^{3} /$ year. Figure 1 shows that in this case, the calculation results using formula (1.1) with a factor of 0.01 reduce the measured flow rate by about 3 times.

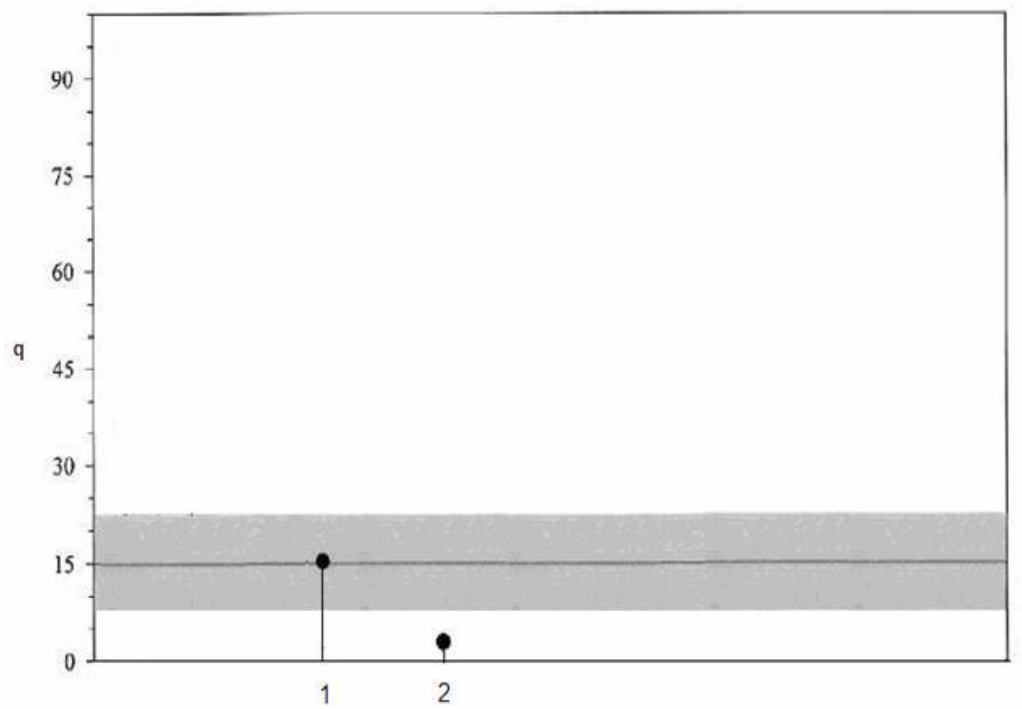

Fig. 1. Comparison of calculation and measurement results of pebble sediment discharge (q - average annual alongshore discharge $\left[10^{3} \mathrm{~m}^{3} /\right.$ year $\left.]\right)$ : 1 - measured discharge; 2 - calculated using $(1.1)$ at $\mathrm{K}=$ 0.01 .

One of the modern numerical models for alongshore transport of pebble sediments is the BOREZED model [2]. It includes a hydrodynamic part and a module for calculating bottom sediment transport. The hydrodynamic part is based on the nonlinear wave equations of shallow water. The sediment transport module uses the Bagnold method. Local and specific sediment discharge rates are summed up in space and time to determine the integral 
alongshore transport. The model is calibrated to the bottom friction coefficient for engineering applications. It requires actual data on pebble transport. In [5], for this model, an algebraic formula was obtained for the volumetric alongshore sediment transport, which includes six coefficients determined further from the data of field measurements:

where

$$
Q_{\text {new }}=c_{0} \frac{1.47}{\rho_{n}-\rho_{w}} H_{s b}^{c 1} T^{c 2} s^{c 3} D_{m}^{c 4} \sin 2 \alpha_{b}^{c 5}
$$

$H_{s b}$ - significant wave height along the collapse line;

$T$ - average wave period;

$s$ - bottom slope;

After substitution of the optimal values for the coefficients $c$, formula (12) takes the following form:

$$
Q_{\text {new }}=1.34 \frac{1.47}{\rho_{n}-\rho_{w}} H_{s b}^{2.49} T^{1.29} s^{0.88} D_{m}^{-0.62} \sin 2 \alpha_{b}^{1.81}
$$

The formula has been verified by field measurements in the ranges of significant wave heights along the breaking line from 0.25 to $2.75 \mathrm{~m}$, average periods from 2.91 to $4.85 \mathrm{~s}$, coastal slopes from 0.04 to 0.12 , average sediment diameters from $0.01 \mathrm{~m}$ to 0.14 , angles of refraction of waves along the breaking line from 2.5 to 20. In total, 37 field measurements were used, and the error of this formula in relation to field data does not exceed $18 \%$.

The distribution of alongshore flow rates determined by formulas (1) with a coefficient 0.01 and formula (13) under various wave and beach conditions are shown in Figures 2-6.

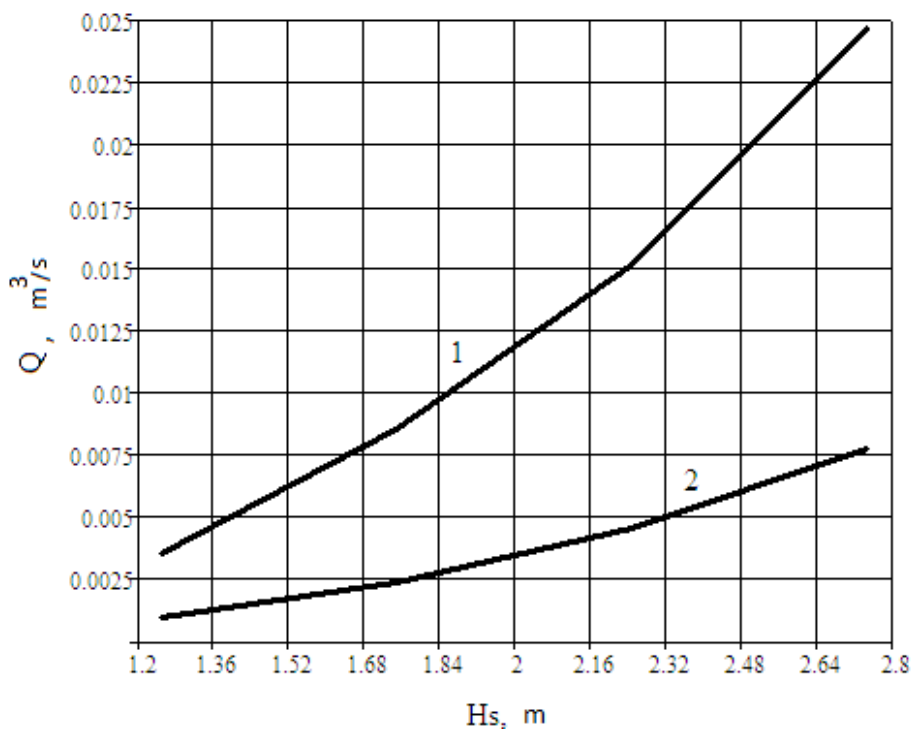

Fig. 2. Distribution of alongshore flow rates at different wave heights: 1 - formula (13); 2 - formula (1) with a coefficient 0.01 . 


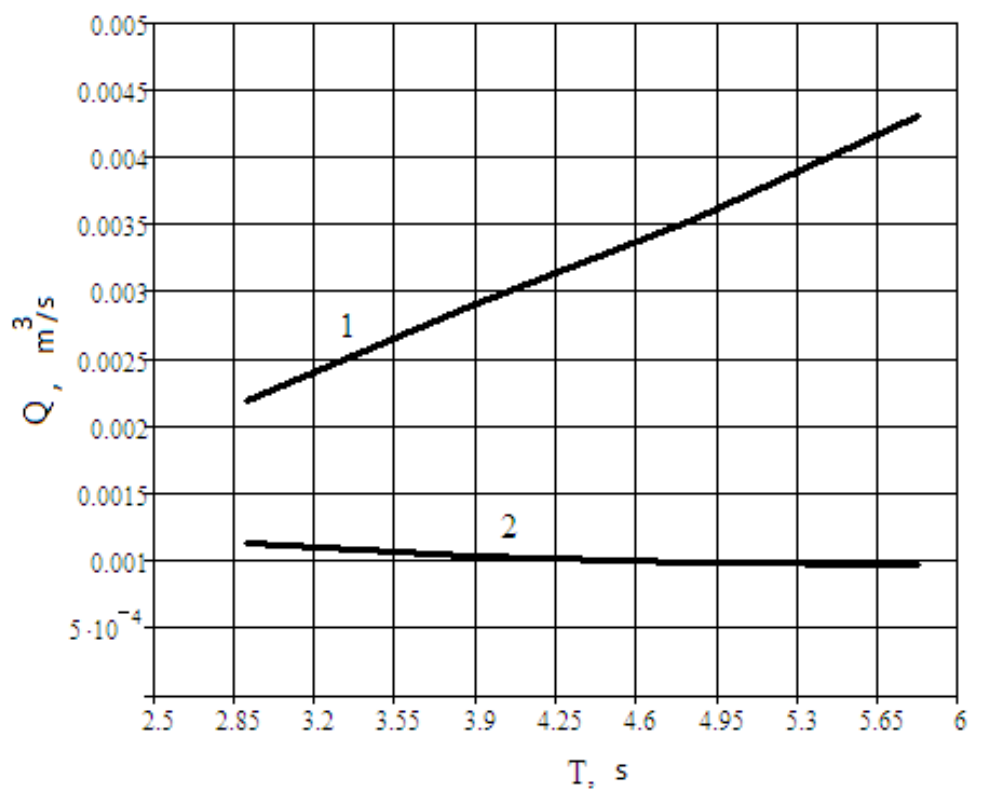

Fig. 3. Distribution of alongshore discharges for different periods: 1 - formula (13); 2 - formula (1) with a coefficient 0.01 .

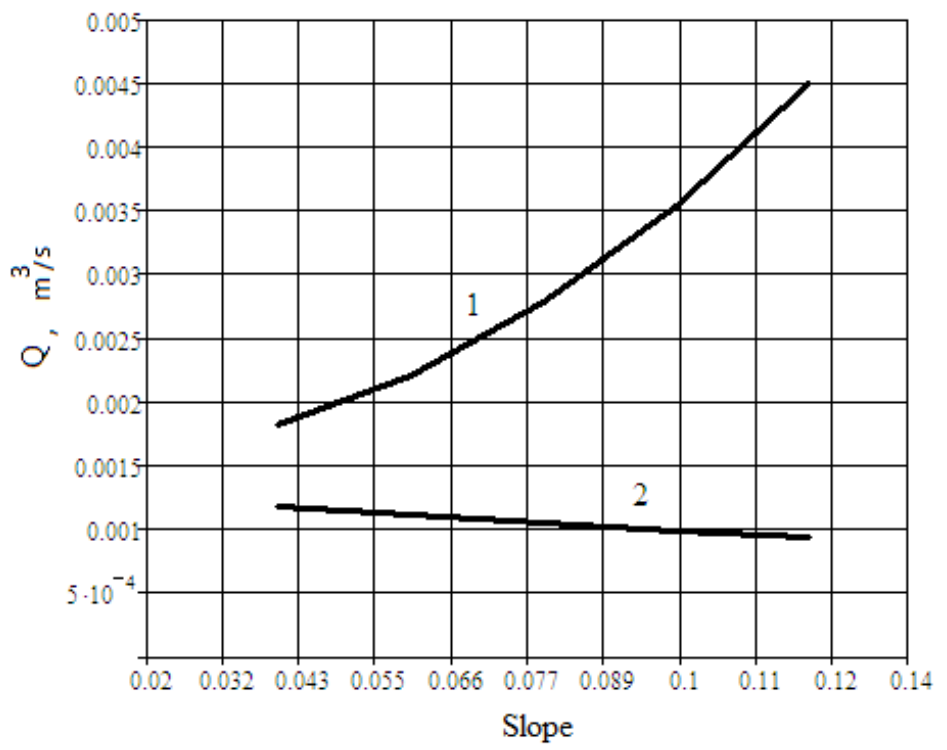

Fig. 4. Distribution of alongshore discharges depending on the slope of the coastal slope: 1 - formula (13); 2 - formula (1) with a coefficient 0.01. 


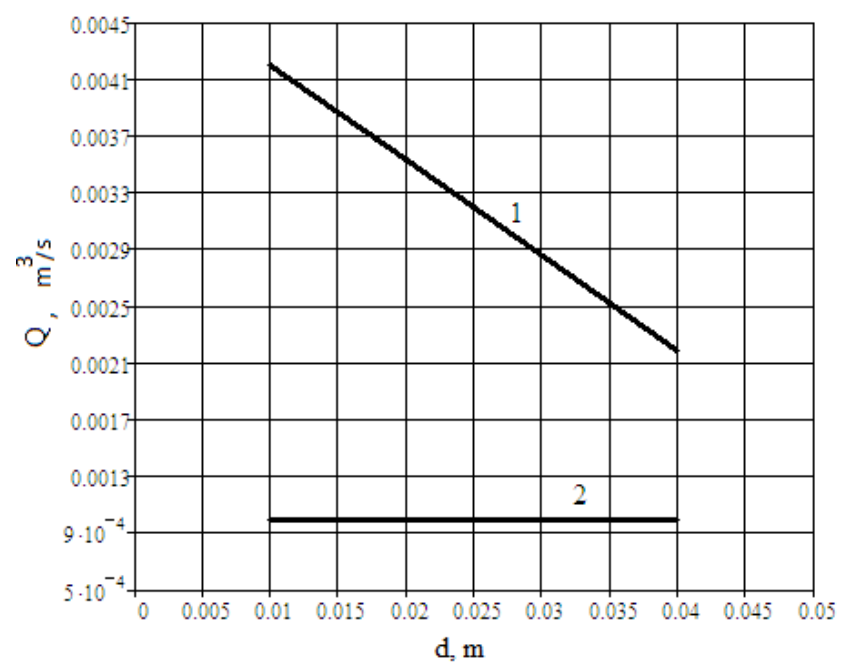

Fig. 5. Distribution of alongshore discharges depending on the size of sediments $(d, m): 1$ - formula (13); 2 - formula (1) with a coefficient 0.01 .

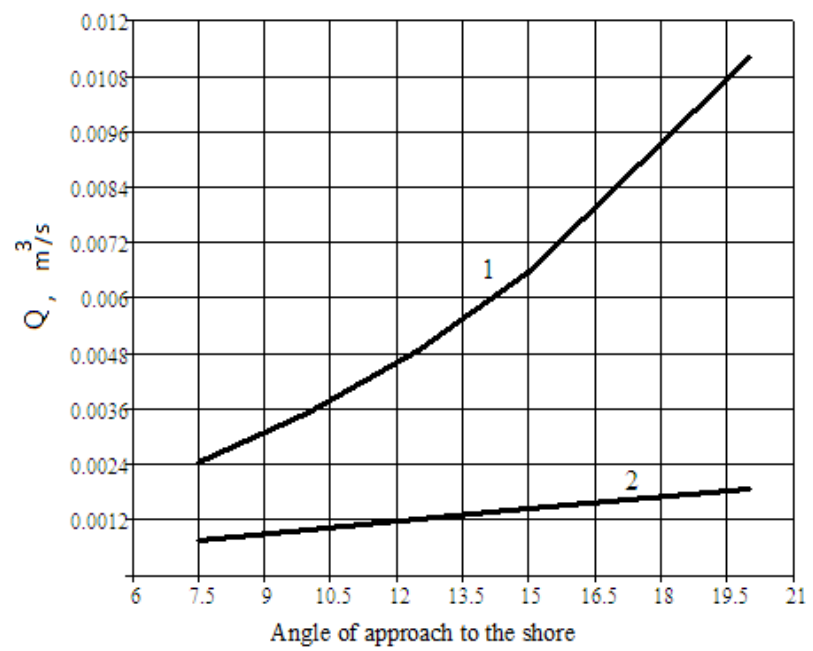

Fig. 6. Distribution of alongshore discharges depending on the angle of approach to the shore: 1 formula (13); 2 - formula (1) with a coefficient 0.01 .

Thus, formula (1) with a coefficient of 0.01 in relation to (12) with a slope of 0.1 gives an erroneous estimate of 2-6 times. This is caused by the fact that this coefficient was obtained on a slope less than 0.1 , and therefore, with a slope of 0.04 , the error according to the formula with a coefficient 0.01 is only $35 \%$.

That is, despite the fact that in [8], there were attempts to use (1) to determine the discharge on pebble beaches, there is still no general coefficient, as for the case of sandy beaches, and there is no theoretical analysis to obtain such coefficients. To use formula (1), it is necessary to first determine the coefficient according to the specific conditions of the selected section of the coast [8].

The situation is similar with the coefficients of the empirical dependencies for pebble beaches, for example, in formula (11). It, like the coefficient 0.01 for (1), needs additional definition in accordance with local conditions. Formula (11), in relation to (1), will have 
closer values in comparison with the measured annual alongshore flow and calculated discharges according to the BOREZED numerical model under conditions of a slope of 0.1 0.12 . This is due to the fact that the coefficient in (11) was obtained experimentally on a section of a pebble beach with an average slope of 0.12 from the breaking line to the top of the wave uprush [31]. But in the case of slopes less than 0.12, the calculation error becomes more significant.

\section{Results}

In connection with the above, a unified approach is proposed to determine the sediment discharge on heterogeneous pebble and sandy beaches, based on modified energy dependences [10].

Modification of the formulas consists in obtaining an empirical coefficient for them, which makes it possible to take into account the differences in hydraulic processes occurring on pebble and sandy beaches [10]. This is due to the fact that the empirical coefficient largely reflects the features of the beaches (lateral slope, the size of the sediments that make up the beach), which form characteristic processes that have a dominant effect on the flow rate. It is assumed that sediments in the coastal zone of the sea are transported under the combined action of waves and currents, which is observed in real conditions in the surf zone [10]. Therefore, when modifying the energy formulas for alongshore sediment rate, the Ackers-White (AW) hydraulic technique [11] is used, modified by I. G. Kantarzhi and S. M. Antsyferov for the conditions of waves propagating in the current [12], and allowing the determination of the total sediment transport, including bottom and suspended sediment [10].

The empirical coefficient of the energy formula for alongshore sediment transport is determined by comparing the value of alongshore sediment rate determined by the AW method with the energy dependence. The determination of the coefficients in the energy dependences completes their modification.

To show the applicability of a unified approach to determining the sediment discharge on pebble and sandy beaches, the developed model of alongshore transport of sandy and pebble sediments was verified based on comparing the results of field measurements with the results determined by the energy formula with the basic empirical coefficient and the coefficient determined using the AW method.

For this purpose, the published data of the wave regime observed over the year and field measurements of the average annual alongshore sediment flow on a section of a pebble beach with a slope of 0.1 and an average diameter of $0.02 \mathrm{~m}$ were used [5].

Table 1 shows the distribution of storms throughout the year.

Table 1. Wave mode per year.

\begin{tabular}{|c|c|c|c|c|}
\hline Storm No. & $\begin{array}{c}\text { Frequency- } \\
\text { repeatability per }\end{array}$ & Period, $\mathrm{s}$ & Collapse height & Approach angle \\
\hline 1 & 2.71 & 3.37 & 0.14 & -10.09 \\
\hline 2 & 1.96 & 3.83 & 0.37 & -14.53 \\
\hline 3 & 0.24 & 4.29 & 0.60 & -16.93 \\
\hline 4 & 0.02 & 4.75 & 0.86 & -17.71 \\
\hline 5 & 3.25 & 3.37 & 0.20 & -9.74 \\
\hline 6 & 2.38 & 3.83 & 0.54 & -13.92 \\
\hline 7 & 0.82 & 4.29 & 0.88 & -16.14 \\
\hline 8 & 0.24 & 4.75 & 1.21 & -17.24 \\
\hline
\end{tabular}




\begin{tabular}{|c|c|c|c|c|}
\hline 9 & 0.04 & 5.22 & 1.55 & -18.36 \\
\hline 10 & 0.04 & 5.68 & 1.90 & -19.19 \\
\hline 11 & 1.85 & 3.37 & 0.25 & -7.23 \\
\hline 12 & 0.92 & 3.83 & 0.67 & -10.30 \\
\hline 13 & 0.92 & 4.29 & 1.09 & -11.89 \\
\hline 14 & 0.25 & 4.75 & 1.48 & -12.89 \\
\hline 15 & 0.12 & 5.22 & 1.87 & -13.66 \\
\hline 16 & 0.03 & 5.68 & 2.24 & -14.35 \\
\hline 17 & 0.03 & 6.14 & 2.65 & -15.25 \\
\hline 18 & 2.07 & 3.37 & 0.27 & -1.38 \\
\hline 19 & 0.96 & 3.83 & 0.71 & -1.96 \\
\hline 20 & 1.07 & 4.29 & 1.15 & -2.26 \\
\hline 21 & 0.80 & 4.75 & 1.50 & -3.57 \\
\hline 22 & 0.77 & 5.22 & 1.88 & -4.43 \\
\hline 23 & 0.55 & 5.68 & 2.27 & -5.32 \\
\hline 24 & 0.13 & 6.14 & 2.68 & -5.66 \\
\hline 25 & 0.02 & 6.60 & 3.09 & -6.60 \\
\hline 26 & 3.62 & 3.37 & 0.25 & 4.25 \\
\hline 27 & 1.84 & 3.83 & 0.65 & 6.03 \\
\hline 28 & 2.03 & 4.29 & 1.05 & 6.98 \\
\hline 29 & 2.10 & 4.75 & 1.43 & 6.38 \\
\hline 30 & 2.51 & 5.22 & 1.79 & 6.19 \\
\hline 31 & 1.42 & 5.68 & 2.12 & 5.17 \\
\hline 32 & 0.83 & 6.14 & 2.44 & 4.75 \\
\hline 33 & 0.30 & 6.60 & 2.77 & 3.52 \\
\hline 34 & 0.01 & 7.07 & 3.17 & 3.69 \\
\hline 35 & 3.63 & 3.37 & 0.19 & 6.77 \\
\hline 36 & 5.44 & 3.83 & 0.49 & 9.67 \\
\hline 37 & 6.61 & 4.29 & 0.80 & 11.20 \\
\hline 38 & 3.47 & 4.75 & 1.11 & 11.28 \\
\hline 39 & 1.81 & 5.22 & 1.41 & 11.02 \\
\hline 40 & 1.00 & 5.68 & 1.71 & 10.44 \\
\hline 41 & 0.27 & 6.14 & 1.98 & 10.45 \\
\hline 42 & 0.01 & 6.60 & 2.29 & 9.62 \\
\hline 43 & 5.87 & 3.37 & 0.13 & 6.68 \\
\hline 44 & 4.85 & 3.83 & 0.33 & 9.60 \\
\hline 45 & 1.28 & 4.29 & 0.54 & 11.08 \\
\hline 46 & 0.55 & 4.75 & 0.76 & 11.49 \\
\hline 47 & 0.06 & 5.22 & 0.96 & 11.34 \\
\hline
\end{tabular}

Since the slope of the studied area corresponds to the deep shores, the coefficient was obtained for formula (1). 
The results of field measurements are compared with the results determined by formula (1) with the basic empirical coefficient and the coefficient determined using the AW method. For comparison, a coefficient 0.01 was chosen, since, in contrast to 0.41 , it is more suitable for these conditions: a coefficient 0.01 was obtained at average slopes and is intended to be used for diameters larger than $1 \mathrm{~mm}$.

When calculating the average annual sediment flow, the discharge from each storm was determined. The integral discharge of all storms, taking into account their frequency, gives the average annual discharge of sediments.

Figure 7 shows the results of comparing the calculated values of the average annual alongshore flow of pebble sediments with the one measured in this area for the year.

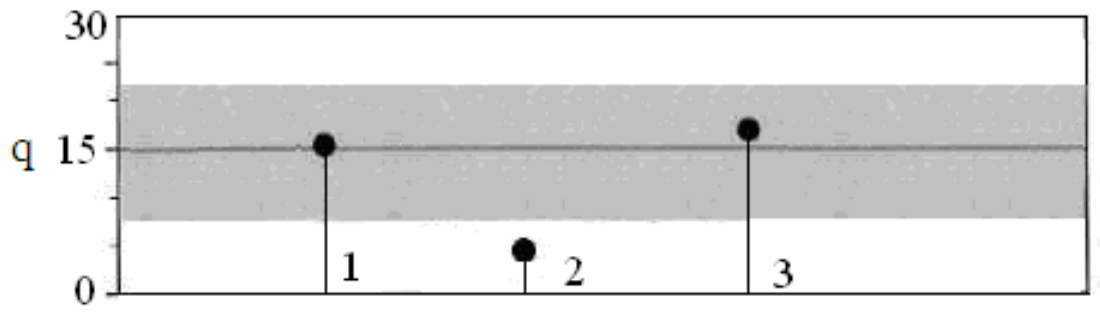

Fig. 7. Alongshore flow of pebble deposits, $\mathrm{q}$ - average annual alongshore discharge $\left[10^{3} \mathrm{~m}^{3} /\right.$ year $]: 1$ - measured discharge; 2 - calculated using (1) at $\mathrm{K}=0.01 ; 3$ - calculated according to the modified formula (1).

The calculation error according to formula (1) using the base coefficient is $60 \%$. And if we replace the coefficient with the one obtained by the proposed method, then the error is reduced to $15 \%$.

\section{Conclusions}

A model of alongshore transport of inhomogeneous sediments has been developed in relation to the conditions of inhomogeneous pebble and sandy beaches, described by modified energy dependences.

It is shown that the dependences for the transfer of riverbed sediments, including the transport of traction and suspension sediment (AW), can be used to calculate the alongshore transport of sediments for the conditions of gravel-pebble-sandy beaches, typical for areas of intensive port construction on the Black Sea coast of Russia.

Based on the results of field studies, the developed model of alongshore transport of heterogeneous sediments was verified and described by modified energy dependences. Using the developed model, the forecast error is $15 \%$ in terms of material consumption.

\section{References}

1. M.C. Quick, P. Dyksterhuis. «Cross-shore transport for beaches of mixed sand and gravel». International Symposium: Waves-physical and numerical modeling. Canadian Society of Civil Engineers, pp. 1443-1452 (1994)

2. A.J. Chadwick, Proceedings of the Institution of Civil Engineers, Part 2 _91, pp. 719737 (1991)

3. O.Luka, G. Tatu, «Environmental impact of free surface flows» (Editura Orizonturi Univer-sitare, Timisoara, Romania, 2002) 
4. I.O. Leontiev, "Coastal dynamics: waves, currents, sediment flows" (M, GEOS,2001)

5. E. Van Wellen, A.J. Chadwick, T. Mason, Coastal Engineering, pp. 243-275 (2000)

6. D.R. Borah, A. Balloffet, Coastal and Ocean Engineering, 111, 4, 645-660 (1985)

7. B. Le Mehaute, M. Soldate, Numerical Model for Predicting Shoreline Changes, Miscellaneous Report No. 80-6, Coastal Engineering Research Center, U.S. Army Corps of Engineers, Fort Belvoir, pp. 72 (1980)

8. V.M. Shahin, Izvestia of VNIIG named after B.E. Vedeneev, 226 (1992)

9. V.A. Petrov, N.A. Yaroslavtsev, Study of alongshore transport of pebble deposits. Water resources (M. 1985)

10. E. Bondareva, E3S Web of Conferences, 224 (2020)

11. P. Ackers, W.R. White, Proceedings of the ASCE, 99. HY11, 2041-2060 (1973)

12. I. G. Kantarzhi, M. S. Antsyferov, Oceanology, 45, 2, 173-181 (2005) 